\title{
Editorial: Aging in Indigenous Populations
}

I am pleased to be able to provide some comments from the Canadian Institutes of Health Research (CIHR) Institute on Aging on this special issue of the Canadian Journal on Aging on the important topic of aging in Indigenous populations.

As you may know, the CIHR Institute of Aging Strategic Plan 2019-21 contains a number of cross-cutting strategic directions. One of these is the integration of an Indigenous perspective on aging in all of our initiatives and actions when it is appropriate.

The Institute is inspired by the many positive Indigenous cultural values related to the role of Elders in the community, in order to better address the stigma associated with aging and the diminished social role that is experienced by older individuals in non-Indigenous communities. The Institute is also inspired by the way that Indigenous researchers include their community in their projects.

The Institute of Aging is committed to incorporating an Indigenous research component, along with Indigenous leadership, into the largest number possible of the strategic initiatives that we lead. The goal is to address the specific health and wellness challenges related to aging that are prevalent among Indigenous populations.

In this special issue of the Canadian Journal on Aging, there are articles that cover a wide range of research themes and topics that include Indigenous Elders, caregivers, intergenerational social engagement, and successful aging. Also included are culturally safe approaches, cultural knowledge and understanding, and community-based participatory research methods. From rural to remote areas and from a diverse range of Indigenous communities, this special issue is inspiring and contains new knowledge about aging and Indigenous people.

I encourage you to watch the excellent video posted on the Canadian Journal on Aging "Aging in Indigenous Populations" page, which summarizes the themes and perspectives covered by this special issue.

I sincerely hope that you will all be enlightened and as inspired by this special issue as I was.

R. Jane Rylett 